\title{
Correlation of vitamin D receptor with bronchial asthma in children
}

\author{
CHUNLEI HOU ${ }^{*}$, XIAOLI ZHU* and XIANGYUN CHANG \\ Department of Pediatrics, Daqing Longnan Hospital, Daqing, Heilongjiang 163453, P.R. China
}

Received August 11, 2017; Accepted December 11, 2017

DOI: 10.3892/etm.2018.5739

\begin{abstract}
This study was designed to investigate the correlation of vitamin D receptor (VDR) gene polymorphism with bronchial asthma in children. Seventy patients admitted to Daqing Longnan Hospital and diagnosed as bronchial asthma for the first time from April 2015 to May 2017 were selected as observation group. Patients received routine treatment and intervention. Seventy healthy subjects admitted to hospital during the same period were enrolled as the control group. Vitamin D gene polymorphism was detected by polymerase chain reactionrestriction fragment length polymorphism assay; the levels of total serum immunoglobulin E (IgE) in the two groups were determined by electrochemiluminescence immunoassay; lung function levels in patients were measured using PowerCube (Germany) pulmonary function instrument before and after treatment, and the relationship between VDR gene polymorphism and lung function in children with bronchial asthma was analyzed. The difference in comparison of base frequency of rs1544410 locus of VDR gene had no statistical significance between the two groups $(\mathrm{P}>0.05)$. The locus $\mathrm{CC}$ frequency of rs7975232 of VDR gene in observation group was lower in the observation group than that in the control group $(\mathrm{P}<0.05)$; the locus AC and AA frequencies of rs7975232 of VDR gene were higher in the observation group than those in the control group $(\mathrm{P}<0.05)$. The level of vitamin $\mathrm{D}$ was lower in the observation group than that in the control group $(\mathrm{P}<0.05)$; the level of total serum $\operatorname{IgE}$ was higher in the observation group than that in the control group $(\mathrm{P}<0.05)$. The forced expiratory volume in $1 \mathrm{sec}$ (FEV1), peak expiratory flow (PEF) and the ratio of FEV1 to forced vital capacity (FVC) in children with bronchial asthma in the observation group were higher after treatment than those before treatment $(\mathrm{P}<0.05)$. The correlation research displayed that VDR gene polymorphism was negatively correlated with
\end{abstract}

Correspondence to: Dr Xiangyun Chang, Department of Pediatrics, Daqing Longnan Hospital, 35 Aiguo Road, Ranghulu, Daqing, Heilongjiang 163453, P.R. China

E-mail: xiangyun_chang@163.com

*Contributed equally

Key words: vitamin D receptor, bronchial asthma in children, correlation lung function levels in children with bronchial asthma $(\mathrm{P}<0.05)$. The results showed that children with bronchial asthma are often accompanied by different degrees of changes in VDR gene polymorphism, which is negatively correlated with the severity of asthma, so vitamin D should be strengthened to ameliorate the prognosis of children.

\section{Introduction}

Bronchial asthma (asthma for short) is a common clinical disease frequently occurring in children, which has become the world's most common chronic respiratory disease, and its incidence and mortality are on the rise in recent years (1). Patients with asthma are clinically manifested by recurrent wheezing, cough and dyspnea, and mainly treated with glucocorticoid inhalation; although this method can suppress disease development rapidly, prevent asthma exacerbation and reduce asthma incidence, the long-term prognosis is poor due to the incomplete knowledge of etiology about asthma plus patients influenced by environment, exercise, mental state and other factors (2,3). A large number of reports have indicated (4) gene polymorphism related to vitamin D metabolism and functional pathway, e.g. mutations in the pigment P45021E gene, vitamin D gene and group-specific component globulin (Gc-globulin) can cause cell abnormalities in vitamin D levels, and the lack of vitamin D can lead to the reduction of lung compliance, resulting in the body's immune abnormality; moreover, VDR gene polymorphism is closely associated with the onset of asthma and severity of the disease; when people are suffering an asthma attack, the proliferation and growth of B lymphocytes is sensed by interleukin-13 (IL-13), which will produce a large number of immunoglobulin $\mathrm{E}$ ( $\mathrm{IgE})$, thus aggravating the occurrence and development of the disease (5). Therefore, to enhance the study on the correlation of VDR gene polymorphism with bronchial asthma in children can assess patient's condition and guide the clinical treatment $(6,7)$. In order to explore the correlation of vitamin D receptor with bronchial asthma in children, 70 patients admitted to hospital and diagnosed as bronchial asthma for the first time from April 2015 to May 2017, and 70 healthy subjects were selected for this study.

\section{Patients and methods}

Clinical data. Seventy patients admitted to Daqing Longnan Hospital and diagnosed as bronchial asthma for the first time 
Table I. Comparisons of frequencies of rs7975232 and rs1544410 loci of VDR gene between two groups [n (\%)].

\begin{tabular}{|c|c|c|c|c|c|c|c|}
\hline \multirow[b]{2}{*}{ Group } & \multirow[b]{2}{*}{ Case } & \multicolumn{3}{|c|}{ rs7975232 } & \multicolumn{3}{|c|}{ rs 1544410} \\
\hline & & $\mathrm{CC}$ & $\mathrm{AC}$ & AA & GG & AG & AA \\
\hline Observation group & 70 & $36(51.43)$ & $30(42.86)$ & $4(5.71)$ & $66(94.29)$ & $4(5.71)$ & $0(0.00)$ \\
\hline Control group & 70 & $65(92.86)$ & $5(7.14)$ & $0(0.00)$ & $65(92.86)$ & $5(7.14)$ & $0(0.00)$ \\
\hline$\chi^{2}$ & I & 5.036 & 6.105 & 5.779 & 0.194 & 1.527 & 0.985 \\
\hline P-value & 1 & $<0.05$ & $<0.05$ & $<0.05$ & $>0.05$ & $>0.05$ & $>0.05$ \\
\hline
\end{tabular}

VDR, vitamin D receptor.

Table II. Comparisons of levels of vitamin D and total serum $\mathrm{IgE}$ between two groups (mean $\pm \mathrm{SD})$.

\begin{tabular}{lccc}
\hline Group & Case & $\begin{array}{c}\text { Vitamin D } \\
(\mathrm{ng} / \mathrm{ml})\end{array}$ & $\begin{array}{c}\text { Total serum } \\
\text { IgE }(\mathrm{ng} / \mathrm{ml})\end{array}$ \\
\hline Observation group & 70 & $16.83 \pm 3.29$ & $523.21 \pm 34.35$ \\
Control group & 70 & $42.12 \pm 6.46$ & $227.53 \pm 21.59$ \\
t-value & $/$ & 18.205 & 17.495 \\
P-value & $/$ & $<0.05$ & $<0.05$ \\
\hline
\end{tabular}

IgE, immunoglobulin E.

from April 2015 to May 2017 were selected as observation group, including 43 males and 27 females, aged 5-12 years, with an average of $8.84 \pm 3.21$ years, and the duration of disease was 1-3 years, with an average of $1.84 \pm 0.57$ years. Inclusion criteria: i) Patients who met clinical diagnostic criteria for pediatric bronchial asthma revised by the Subspecialty Group of Respiratory Diseases, the Society of Pediatrics, Chinese Medical Association in 2008 (8,9); ii) patients with confirmed diagnosis by biochemical indexes and imaging examination; iii) children who were diagnosed for the first time, regardless of sex. Exclusion criteria: i) Patients who did not meet the clinical diagnosis and inclusion criteria of newly diagnosed bronchial asthma; ii) patients who had incomplete data or difficulty in cooperation with diagnosis and treatment; iii) patients who were complicated with serious heart, liver and kidney dysfunction or mental disorder. Seventy healthy subjects admitted to hospital during the same period were enrolled as control group, including 37 males and 33 females, aged 5-11 years, with an average of $8.04 \pm 3.01$ years. The project was approved and supervised by the Ethics Committee of Daqing Longnan Hospital, and patients signed the informed consent. The differences in comparisons of sex and age between two groups were not statistically significant $(\mathrm{P}>0.05)$, so the data were comparable.

Methods. i) Collection of specimen. Four milliliters fasting venous blood was extracted from observation group the next morning after admission, and $4 \mathrm{ml}$ fasting venous blood was drawn from subjects in control group on the day of heath examination. The specimens were placed into separation gel tube and Ethylene Diamine Tetraacetic Acid-2K (EDTA-2K) anticoagulation tube with each tube of $2 \mathrm{ml}$. ii) Methods of
Table III. Comparisons of levels of lung function before and after treatment in the observation group (mean $\pm \mathrm{SD}$ ).

\begin{tabular}{lccc}
\hline Time-point & $\begin{array}{c}\text { FEV1 } \\
(\text { liters })\end{array}$ & $\begin{array}{c}\text { FEV1/FVC } \\
(\%)\end{array}$ & $\begin{array}{c}\text { PEF } \\
(1 / \mathrm{min})\end{array}$ \\
\hline Before treatment & $1.611 \pm 0.322$ & $52.12 \pm 5.12$ & $53.25 \pm 5.31$ \\
After treatment & $1.99 \pm 0.62^{\mathrm{a}}$ & $63.25 \pm 6.41^{\mathrm{a}}$ & $65.36 \pm 6.27^{\mathrm{a}}$ \\
t-value & 16.396 & 17.105 & 15.903 \\
P-value & $<0.05$ & $<0.05$ & $<0.05$ \\
\hline
\end{tabular}

FEV1, forced expiratory volume in $1 \mathrm{sec}$; FVC, forced vital capacity; $\mathrm{PEF}$, peak expiratory flow. ${ }^{\mathrm{a}} \mathrm{P}<0.05$ compared with that before treatment.

detection. The collected specimens were taken to detect VDR gene polymorphism using polymerase chain reaction-restriction fragment length polymorphism assay. The primers, rs7975232 and rs1544410 loci of VDR gene, were selected as candidate loci. The primers were synthesized, of which rs1544410 was in accordance with VDR gene sequence in GenBank, and rs1544410 was completed on the automated DNA synthesizer by Shanghai Biological Engineering Technology Service Co., Ltd. (Shanghai, China), followed by purification with denaturing polyacrylamide gel and detection of single nucleotide polymorphism (SNP) site in products of polymerase chain reaction (PCR) using ABI3730 Sequence Analyzer (USA); the levels of total serum IgE in the two groups were determined by electrochemiluminescence immunoassay, and the related operations were completed strictly according to kits (Huashun Biological Engineering Co., Ltd., Shanghai, China) and the instruments $(10,11)$; iii) detection of lung function. Lung function indexes, including forced expiratory volume in $1 \mathrm{sec}$ (FEV1), the ratio of FEV1 to forced vital capacity (FVC) and peak expiratory flow (PEF), were measured using PowerCube (Germany) pulmonary function instrument before treatment and at 14 days after treatment $(2,12)$.

Observational indexes. i) Genotypes. The frequency distributions of rs7975232 and rs1544410 loci of VDR gene in observation group and control group were observed. ii) Levels of vitamin D and total serum IgE. The levels of vitamin D and total serum IgE in two groups were observed. iii) Lung function levels. The lung function levels in patients with bronchial asthma before and after intervention were observed. 
Table IV. Comparisons of correlations of VDR gene polymorphism with lung function levels in children with bronchial asthma ( $\mathrm{r}$ and $\mathrm{p})$.

\begin{tabular}{lcrrr}
\hline Correlation & FEV1 & FEV1/FVC & FEV1 & \multicolumn{1}{c}{ PEF } \\
\hline rs7975232 & $-1.463(0.034)$ & $-0.896(0.043)$ & $-2.527(0.029)$ & $-1.031(0.038)$ \\
rs1544410 & $5.396(0.073)$ & $4.389(0.086)$ & $5.015(0.059)$ & $4.992(0.042)$ \\
\hline
\end{tabular}

FEV1, forced expiratory volume in $1 \mathrm{sec}$; FVC, forced vital capacity; PEF, peak expiratory flow.

iv) Correlation. The correlation of vitamin $\mathrm{D}$ and lung function levels in patients with bronchial asthma was observed.

Statistical analysis. Data were processed by SPSS 18.0 software (SPSS, Inc., Chicago, IL, USA). Enumeration data were analyzed by Chi-square test and expressed as $\mathrm{n}$ (percentage, \%). Measurement data were analyzed by t-test before and after treatment and expressed as mean \pm standard deviation (mean \pm SD). SPSS Pearson's correlation analysis was adopted for factors affecting VDR gene polymorphism. $\mathrm{P}<0.05$ was considered to indicate a statisticaly significant difference.

\section{Results}

Comparison offrequencies of rs 7975232 and rs 1544410 loci of VDR gene between two groups. The difference in comparison of base frequency of rs1544410 locus of VDR gene had no statistical significance between the two groups $(\mathrm{P}>0.05)$. The locus CC frequency of rs7975232 of VDR gene was lower in the observation group than that in the control group $(\mathrm{P}<0.05)$; the loci AC and AA frequencies of rs7975232 of VDR gene were higher in the observation group than those in the control group $(\mathrm{P}<0.05)($ Table I).

Comparison of levels of vitamin $D$ and total serum IgE between two groups. The level of vitamin D was lower in the observation group than that in the control group $(\mathrm{P}<0.05)$; the level of total serum IgE was higher in the observation group than that in the control group $(\mathrm{P}<0.05)$ (Table II).

Comparison of levels of lung function before and after treatment in the observation group. FEV1, PEF and the ratio of FEV1 to FVC in children with bronchial asthma in the observation group were higher after treatment than those before treatment $(\mathrm{P}<0.05)$ (Table III).

Comparison of correlations of VDR gene polymorphism with lung function levels in children with bronchial asthma in the observation group. The correlation research displayed that VDR gene polymorphism rs7975232 was negatively correlated with lung function levels in children with bronchial asthma $(\mathrm{P}<0.05)$; there was no correlation of rs 1544410 with lung function levels in patients with bronchial asthma $(\mathrm{P}>0.05)$ (Table IV).

\section{Discussion}

Bronchial asthma is a common disease in the clinical practice, it is a chronic allergic airway disease involved by multiple cells and cell components together $(13,14)$. Currently, the clinical pathogenesis of bronchial asthma is not completely known, which is generally considered that it is related to immune, heredity, environment and other factors; it is a disease of multifactorial inheritance, and clinically displays multi-factors and heterogeneity when patients suffer attack of the disease (13). VDR, also known as anti-rachitic vitamin, is one of the second steroid hormones, and synthesized by skin and obtained from food for a small amount. Vitamin D contains five compounds, including VD2 and VD3, closely related to human health, and it is a member of the steroid/thyroid hormone receptor superfamily $(15,16)$. Additionally, vitamin D, as a selective regulator of the immune system, affects the balance of the ratio of T helper 1 cells (Th1) to Th2 and causes the immune balance of Th17/T regulator cells (Treg). The literature reported that airway hyperresponsiveness and airway remodeling are important features of asthma, and vitamin D inhibits smooth muscle hyperplasia thus affecting airway remodeling and lung function. At present, ample literature has reported gene polymorphism related to vitamin D metabolism and functional pathway; therein, pigment P45021R1 gene and vitamin D gene are able to affect the level of vitamin D levels. In this study, the difference in comparison of base frequency of rs1544410 locus of VDR gene had no statistical significance between two groups $(\mathrm{P}>0.05)$. The locus $\mathrm{CC}$ frequency of rs7975232 of VDR gene was lower in the observation group than that in the control group $(\mathrm{P}<0.05)$; the loci $\mathrm{AC}$ and $\mathrm{AA}$ frequencies of rs7975232 of VDR gene were higher in the observation group than those in the control group $(\mathrm{P}<0.05)$, indicating that VDR gene polymorphism has obvious difference in the frequency distribution in bronchial asthma. VDR gene is located on q12-23 loci on chromosome 12, which can be combined with VDR receptor in the target cells, so as to adjust the structure of the corresponding gene $(17)$. It has been reported that $(18,19)$ the expression of VDR is associated with pulmonary microenvironment development, that is, when there is a lack of VDR, while it is simulated by inflammatory factor, the simulation of lung inflammation is relatively light, revealing that the lack of VDR plays a protective role on asthma. In this study, the level of vitamin $\mathrm{D}$ was lower in the observation group than that in the control group $(\mathrm{P}<0.05)$; the level of total serum $\operatorname{IgE}$ was higher in the observation group than that in the control group $(\mathrm{P}<0.05)$, indicating that vitamin $\mathrm{D}$ can mediate body's immunity, which is conducive to assessing the severity of the disease.

The literature shows that (20) the occurrence and development of asthma is a multifactorial process that is caused by the imbalance of Th1/Th2 in the body; when patients suffer asthma, $\mathrm{T}$ helper cells in the body differentiate into 
Th2, making overexpression of type Th2 cytokines, so as to increase the level of $\mathrm{IgE}$ and promote the accumulation of eosinophils in the airways thus producing airway responses. Vitamin D not only is the key regulator of bone metabolism and calcium homeostasis of the body, but also belongs to the second steroid hormones, which plays an important role in the immune regulation and can be directly involved in the secretion of cytokines and regulate Th1/Th2 shift, thus helping to relieve the clinical symptoms of patients (21). It is reported that (22) the deficiency and insufficiency of vitamin D indicate that it is of great importance in the occurrence and development of bronchial asthma in children and can induce allergic factors thus leading to asthma, which is one of the risk factors in asthma. The correlation research in this study displayed that VDR gene polymorphism rs7975232 was negatively correlated with lung function levels in children with bronchial asthma $(\mathrm{P}<0.05)$; there was no correlation of rs 1544410 with lung function levels in patients with bronchial asthma $(\mathrm{P}>0.05)$, revealing that the level of vitamin $\mathrm{D}$ can respond to the change of disease thus correctly evaluating the prognosis of patients; moreover, to strengthen the determination of vitamin D level can guide the clinical treatment, which is able to make the treatment in patients more targeted. However, for the ineffective single test of vitamin $\mathrm{D}$, the combination with other indexes can be utilized, so as to exert the advantages of different indexes to be more accurate in response to the changes of the patient's illness (23).

In conclusion, children with bronchial asthma are often accompanied by different degrees of changes in VDR gene polymorphism, which is negatively correlated with the severity of asthma, so vitamin D should be strengthened to ameliorate the prognosis of children.

\section{Competing interests}

The authors declare that they have no competing interests.

\section{References}

1. Yadav M and Mittal K: Effect of vitamin D supplementation on moderate to severe bronchial asthma. Indian J Pediatr 81: 650-654, 2014.

2. Blasi F, Tarsia P, Mantero M, Morlacchi LC and Piffer F: Cefditoren versus levofloxacin in patients with exacerbations of chronic bronchitis: Serum inflammatory biomarkers, clinical efficacy, and microbiological eradication. Ther Clin Risk Manag 9: 55-64, 2013.

3. Molyneux E, Riordan FA and Walsh A: Acute bacterial meningitis in children presenting to the Royal Liverpool Children's Hospital, Liverpool, UK and the Queen Elizabeth Central Hospital in Blantyre, Malawi: A world of difference. Ann Trop Paediatr 26: 29-37, 2006.

4. Turkeli A, Ayaz O, Uncu A, Ozhan B, Bas VN, Tufan AK, Yilmaz $\mathrm{O}$ and Yuksel H: Effects of vitamin D levels on asthma control and severity in pre-school children. Eur Rev Med Pharmacol Sci 20: 26-36, 2016.

5. Breton MC, Beauchesne MF, Lemière C, Rey É, Forget A and Blais L: Risk of perinatal mortality associated with inhaled corticosteroid use for the treatment of asthma during pregnancy. J Allergy Clin Immunol 126: 772-777.e2, 2010.

6. Randolph AG, Yip WK, Falkenstein-Hagander K, Weiss ST, Janssen R, Keisling S and Bont L: Vitamin D-binding protein haplotype is associated with hospitalization for RSV bronchiolitis. Clin Exp Allergy 44: 231-237, 2014.

7. Zhang JG, Chen XJ, Liu T and Jiang SJ: FOXP3(+) associated with the pro-inflammatory regulatory $\mathrm{T}$ and $\mathrm{T}$ helper 17 effector cells in asthma patients. Exp Ther Med 12: 2753-2758, 2016.
8. Serisier DJ: Risks of population antimicrobial resistance associated with chronic macrolide use for inflammatory airway diseases. Lancet Respir Med 1: 262-274, 2013.

9. Nowak RM, Pensler MI, Sarkar DD, Anderson JA, Kvale PA, Ortiz AE and Tomlanovich MC: Comparison of peak expiratory flow and FEV1 admission criteria for acute bronchial asthma. Ann Emerg Med 11: 64-69, 1982.

10. Areeshi MY, Mandal RK, Dar SA, Alshahrani AM, Ahmad A, Jawed A, Wahid M, Lohani M, Panda AK and Haque S: A reappraised meta-analysis of the genetic association between vitamin D receptor BsmI (rs1544410) polymorphism and pulmonary tuberculosis risk. Biosci Rep 37: pii: BSR20170247, 2017.

11. Hung $\mathrm{CH}$, Chiu YC, Hu TH, Chen $\mathrm{CH}$, Lu SN, Huang CM, Wang JH and Lee CM: Significance of vitamin D receptor gene polymorphisms for risk of hepatocellular carcinoma in chronic hepatitis C. Transl Oncol 7: 503-507, 2014.

12. Freire ID, Abreu E Silva FA and Araújo MA: Comparison among pulmonary function test results, the Shwachman-Kulczycki score and the Brasfield score in patients with cystic fibrosis. J Bras Pneumol 34: 280-287, 2008.

13. Nahori MA, Lagranderie M, Lefort J, Thouron F, Joseph D, Winter N, Gicquel B, Lapa e Silva JR and Vargaftig BB: Effects of Mycobacterium bovis BCG on the development of allergic inflammation and bronchial hyperresponsiveness in hyper-IgE BP2 mice vaccinated as newborns. Vaccine 19: 1484-1495, 2001.

14. Han RF, Li HY, Wang JW and Cong XJ: Study on clinical effect and immunologic mechanism of infants capillary bronchitis secondary bronchial asthma treated with bacterial lysates Broncho-Vaxom. Eur Rev Med Pharmacol Sci 20: 2151-2155, 2016.

15. Jiang K, Lu XX, Wang Y, Chen HB and Shu LH: Relationship between serum 25-hydroxyl-vitamin D3 levels and galectin-3 levels in serum and bronchoalveolar lavage fluid in children with asthma. Zhongguo Dang Dai Er Ke Za Zhi 17: 1301-1305, 2015 (In Chinese).

16. Kumar R, Gupta N, Kanuga J and Kanuga M: A comparative study of skin prick test versus serum-specific IgE measurement in indian patients with bronchial asthma and allergic rhinitis. Indian J Chest Dis Allied Sci 57: 81-85, 2015.

17. Liu M, Liu GY, Hu SY, Wan LL, Cai HY, Xu YL, Mao B, Zhu MY, Cui LY and Sun JM: Treatment of mild-to-moderate bronchial asthma (Heat Wheezing syndrome) patients at acute onset with Western Medicine Combined Danlong Oral Liquid: A multi-center, randomized double-blinded, positive-controlled clinical trial. Zhongguo Zhong Xi Yi Jie He Za Zhi 35: 529-533, 2015 (In Chinese).

18. Luong KV and Nguyen LT: Beneficial role of vitamin D3 in the prevention of certain respiratory diseases. Ther Adv Respir Dis 7: 327-350, 2013.

19. Carroll KN, Gebretsadik T, Larkin EK, Dupont WD, Liu Z, Van Driest S and Hartert TV: Relationship of maternal vitamin D level with maternal and infant respiratory disease. Am J Obstet Gynecol 205: 215.e1-215.e7, 2011.

20. Guo HW, Yun CX, Hou GH, Du J, Huang X, Lu Y, Keller ET, Zhang J and Deng JG: Mangiferin attenuates TH1/TH2 cytokine imbalance in an ovalbumin-induced asthmatic mouse model. PLoS One 9: e100394, 2014.

21. Xiao W, Yu H and Zheng C: The imbalance of Th1/Th2 cytokine expression in peripheral blood mononuclear cell from asthmatic patients and the effect of erythromycin on these cytokines. Zhonghua Jie He He Hu Xi Za Zhi 23: 347-350, 2000 (In Chinese).

22. Goodall EC, Granados AC, Luinstra K, Pullenayegum E, Coleman BL, Loeb M and Smieja M: Vitamin D3 and gargling for the prevention of upper respiratory tract infections: A randomized controlled trial. BMC Infect Dis 14: 273, 2014.

23. Sasaki A, Ouchi K, Makata H, Hashimoto K, Matsubara T and Furukawa S: The effect of inhaled corticosteroids on Chlamydophila pneumoniae and Mycoplasma pneumoniae infection in children with bronchial asthma. J Infect Chemother 15: 99-103, 2009.

This work is licensed under a Creative Commons Attribution-NonCommercial-NoDerivatives 4.0 International (CC BY-NC-ND 4.0) License. 